Check for updates

Cite this: RSC Adv., 2017, 7, 46306

Received 17th August 2017

Accepted 22nd September 2017

DOI: $10.1039 / c 7 r a 09094 c$

rsc.li/rsc-advances

\section{Enhancement of thermal conductivity in polyamide-6/graphene composites via a "bridge effect" of silicon carbide whiskers $\uparrow$}

\begin{abstract}
Na Song, $\dagger^{*}$ Haidong Pan, + Xingshuang Hou, Siqi Cui, Liyi Shi and Peng Ding*
It is urgent to manufacture a polymer composite that has high thermal conductivity and mechanical properties simultaneously to meet the heat dissipation requirement of electronic devices. In this paper, we report a bridge effect of Silicon Carbide whiskers ( $\mathrm{SiCW}$ ) on the enhancement of thermal conductivity (TC) in polyamide-6/graphene (PG) composites. The composite was made by melting, stirring through an Internal mixer. Experimental results show that the TC of the PG composites increases with additional introduction of SiCw, particularly in the through-plane direction. For example, based on the PG-2 sample (2 wt\% graphene in polyamide-6 (PA) matrix), the thermal conductivity enhancement (TCE) of PASC-24 (similar to $2 \mathrm{wt} \%$ graphene and $43.2 \mathrm{wt} \% \mathrm{SiCw}$ in the PA matrix) in the through-plane direction is $199 \%$, while in contrast, the TCE in the in-plane direction is just $5.4 \%$. Meanwhile, the mechanical properties of the composites are synchronously enhanced, indicating that it is a convenient method and can be widely applied in various thermal interface materials (TIMs) and thermal management systems.
\end{abstract}

\section{Introduction}

With the application and development of electronic products, effective thermal management technology has become the key to the normal operation of electronic products in many fields. ${ }^{1-3}$ Polymer composites with light weight, corrosion resistance, low cost, easy processing, etc. are widely used in various electronic devices, such as light-emitting diode devices, batteries and communication equipment. ${ }^{4,5}$ However, most polymers have low thermal conductivity $\left(0.1-0.5 \mathrm{~W} \mathrm{~m}^{-1} \mathrm{~K}^{-1}\right)$, far below the demand of thermal conductivity of most electronic products. ${ }^{4,6,7}$ Many researchers have tried to combine nanoscale thermally conductive fillers and polymers to improve the TC., ${ }^{8,9}$

Graphene has extraordinarily high in-plane thermal conductivity (2000-5000 $\mathrm{W} \mathrm{m}^{-1} \mathrm{~K}^{-1}$ near room temperature), mechanical strength, and ultralarge specific surface area. Within several years since discovered, graphene has been widely applied to various fields on account of these unique properties. ${ }^{10-13}$ It has been proved that the TC of the composites can be greatly enhanced by introducing graphene into polymer. ${ }^{14-17}$ Park et al. ${ }^{18}$ reported a TCE of $90 \%$ in polystyrene composites just with $10 \mathrm{vol} \%$ of graphene. However, the heat conduction of graphene exhibits pronounced anisotropy, the TC in the in-

Research Center of Nanoscience and Nanotechnology, Shanghai University, 99 Shangda Road, Shanghai 200444, P. R. China. E-mail: snlxf@shu.edu.cn; dingpeng@shu.edu.cn

$\uparrow$ Electronic supplementary information (ESI) available. See DOI: 10.1039/c7ra09094c

\$ These authors contributed equally to this work. plane direction $\left(\lambda_{x}\right)$ exceeds its TC in the through-plane direction $\left(\lambda_{z}\right)$ counterpart by three orders of magnitude, whereas the value is about $5 \mathrm{~W} \mathrm{~m}^{-1} \mathrm{~K}^{-1}{ }^{19}$, quite evidently, the low $\lambda_{z}$ of graphene composites limits its wider application. Many researchers have adopted various methods to improve the $\lambda_{z}$ of polymer/graphene composites, our group ${ }^{14}$ reported a method that the covalent modification of graphene can improve the $\lambda_{z}$ of PA composites from 0.29 to $0.41 \mathrm{~W} \mathrm{~m}^{-1} \mathrm{~K}^{-1}$, increased by $41.4 \%$. Yuan et al. ${ }^{20}$ reported that the combined use of tetrapodshaped zinc oxide (T-ZnO) whiskers and boron nitride (BN) flakes can improve the $\lambda_{z}$ of phenolic formaldehyde resin (PF), the maximum $\lambda_{z}$ of $1.48 \mathrm{~W} \mathrm{~m}^{-1} \mathrm{~K}^{-1}$ is observed with a T$\mathrm{ZnO}: \mathrm{BN}$ mass ratio of $1: 9$ (the total mass is $60 \mathrm{wt} \%$ ) which is $35.8 \%$ higher than that of $\mathrm{PF} / \mathrm{BN}$ binary composite. Both of them builded a thermal path in the through-plane direction, however, neither the TC or TCE is pretty well. Hence, how to fabricate a polymer/graphene composite that has a high TC in the through-plane direction is necessary and urgent.

In this paper, we report a bridge effect of $\mathrm{SiCw}$ on the enhancement of TC in the PG composites. That the TC of the PG composites increases with additional introduction of $\mathrm{SiCw}$, particularly in the longitudinal direction. It is due to that 1-D SiCw could filled the gap between the 2-D graphene nanosheets to prevent the accumulation of graphene, and a thermally conductive path is additionally constructed in the longitudinal direction. ${ }^{21,22}$ With the help of hot pressing, the combination of the filler and the matrix is more tight, ${ }^{23}$ these effectively reduce the interface thermal resistance. With $2 \mathrm{wt} \%$ graphene in the PA composites, the $\lambda_{z}$ is $0.52 \mathrm{~W} \mathrm{~m}^{-1} \mathrm{~K}^{-1}$, and the $\lambda_{z}$ of PASC-24 is $1.55 \mathrm{~W} \mathrm{~m}^{-1} \mathrm{~K}^{-1}$ with similar graphene content, the TCE is 
$199 \%$. While, the $\lambda_{x}$ of the above composites increases from $7.11 \mathrm{~W} \mathrm{~m}^{-1} \mathrm{~K}^{-1}$ to $7.49 \mathrm{~W} \mathrm{~m}^{-1} \mathrm{~K}^{-1}$, the TCE is just $5.4 \%$. The PASC composites have high values of $\lambda_{z}$ and $\lambda_{x}$ simultaneously, the maximum TC presented in the PASC-4 (9 $\mathrm{wt} \%$ graphene and $36 \mathrm{wt} \% \mathrm{SiCw}$ in the PA matrix) can reach 2.31 and $8.55 \mathrm{~W} \mathrm{~m}^{-1}$ $\mathrm{K}^{-1}$ in the two direction, compared with the pure PA, the TCE is $508 \%$ and $187 \%$, respectively. Meanwhile, the mechanical properties of the composites are synchronously enhanced, the Young's modulus and microhardness of the PA composites increase from 2.11 to $4.98 \mathrm{GPa}$ and 0.11 to $0.214 \mathrm{GPa}$, increased by 136 and $94.5 \%$, respectively. The high $\lambda_{x}$ and $\lambda_{z}$ of the PASC composites, especially the enhancement of $\lambda_{z}$ and mechanical properties is rarely reported in other literature before, and it can be applied in TIMs, connectors and other high-performance thermal management systems.

\section{Experimental}

\section{Materials}

PA slices were purchased from SINOPEC BALING COMPANY, whose density is $1.128 \mathrm{~g} \mathrm{~cm}^{-3}$; graphene nanosheets were provided by LEVSON(Shanghai, China); SiC whiskers were purchased from SHENGNA COMPANY(Shanghai, China), whose purity is $99 \%$ and the aspect ratio is 20 .

\section{Preparation of PA composites}

PA composites were prepared via melt-blending process described as below (schematically represented in the Fig. 1).

Firstly, the PA slices were dried in an oven at $90{ }^{\circ} \mathrm{C}$ for 2 hours. Secondly, PA slices were blended with graphene in a Internal mixer with graphene content of $10 \mathrm{wt} \%$ to obtain PG masterbatch (blended at $230{ }^{\circ} \mathrm{C}$ for $5 \mathrm{~min}$ at a rotation speed of $45 \mathrm{rpm}$ ). Eventually, the PG masterbatch was blended with PA slices with $0.1 \mathrm{wt} \%, 0.5 \mathrm{wt} \%, 1 \mathrm{wt} \%, 2 \mathrm{wt} \%$ and $3 \mathrm{wt} \%$ of graphene in the Internal mixer, respectively, and then the PG composites were obtained. The samples were named PG-0.1, PG-0.5, PG-1, PG-2, PG-3.
Under the condition that the total filling (graphene and $\mathrm{SiCw}$ ) amount is $45 \mathrm{wt} \%$, the filler and PA were prepared by melt blending under the same processing conditions as above. The resulting product had a gravimetric ratio of SiCw to graphene is $1: 0,24: 1,8: 1,4: 1$, respectively, which was name PASC-0, PASC-24, PASC-8, PASC-4, the content of graphene in each component is $0 \mathrm{wt} \%, 1.8 \mathrm{wt} \%, 5 \mathrm{wt} \%, 9 \mathrm{wt} \%$, respectively.

The fabrication of the PA composites testing materials is depicted as follows: (1) putting the composites in the mold in a flat vulcanizing machine (2) melting at $220{ }^{\circ} \mathrm{C}$ for $10 \mathrm{~min}$ to soften the material (3) degassing three times (4) pressing under $15 \mathrm{MPa}$ for $10 \mathrm{~min}$ (5) cooling under $15 \mathrm{MP}$ and then stripping. A cylindrical thermal conductive test sample $(12.7 \mathrm{~mm}$ diameter and approximately $1.7 \mathrm{~mm}$ thickness) was obtained to test the $\lambda_{z}$, and then the samples with $25 \mathrm{~mm}$ diameter and $40 \mu \mathrm{m}$ thickness were acquired by mold compression between two parallel plates to test the $\lambda_{x}$ (Fig. 2).

\section{Characterization}

Fourier transform infrared (FTIR) spectra were recorded on an AVATAR370 Fourier infrared spectrometer using potassium

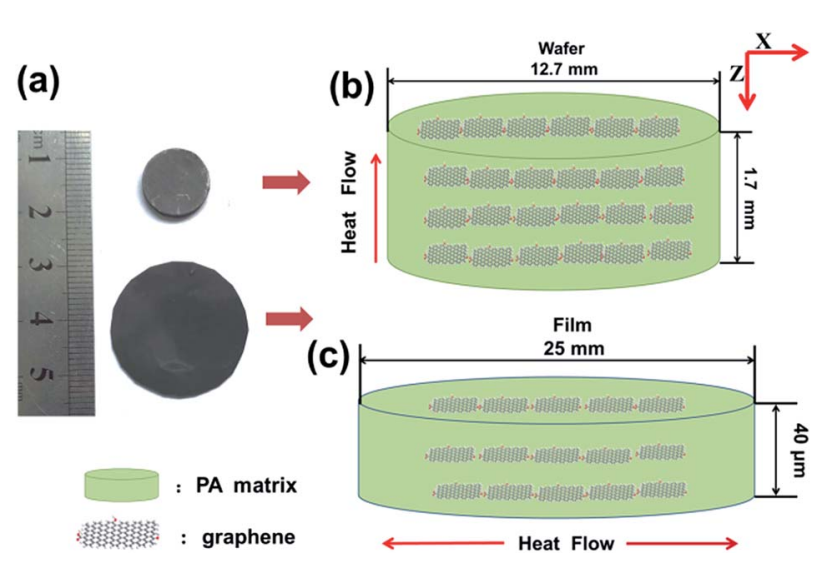

Fig. 2 (a) The photographic images of samples, illustration of (b) samples for $\lambda_{z}$ and (c) samples for $\lambda_{x}$.

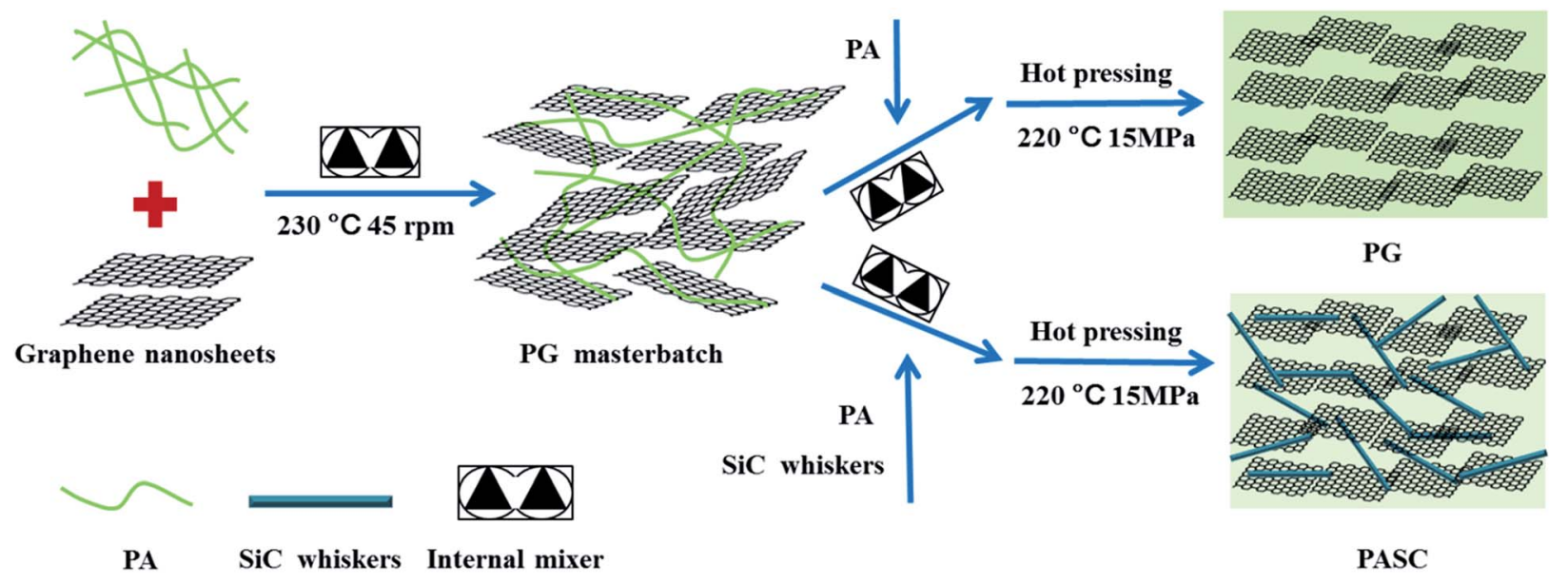

Fig. 1 The preparation flow chart of the PA composites. 
bromide pellets. Raman spectra were obtained using an INVIA confocal micro Raman spectrometer with a $633 \mathrm{~nm}$ laser. X-ray diffraction (XRD) patterns were collected by a D/MAX2500/PC Xray diffractometer with $\mathrm{Cu}-\mathrm{K}_{\alpha}$ radiation $(\lambda=0.154 \mathrm{~nm})$. Transmission electron microscopy (TEM) graphs were acquired under a 200CX transmission electron microscope. High-resolution transmission electron microscopy (HRTEM) was acquired by JEM-2010F, scanning electron microscopy (SEM) images were acquired with a JSM-7500F emission scanning electron microscope. The size of graphene nanosheets were determined by nanoparticle size analyzer (Mastersizer 2000 Malvern Instruments, U.K). Micro-mechanical properties measurements were carried out using a microhardness tester Triboindenter (Hysiror Co., Ltd, USA). The thermal conductivities of the nanocomposites were measured by a Netzsch LFA 447 Nanoflash at $25{ }^{\circ} \mathrm{C}$. $\lambda_{z}$ and $\lambda_{x}$ were determined by measuring the heat flux and the differential temperature across the samples. The test was repeated at least six times for each nanocomposite to ensure data accuracy and reproducibility.

\section{Results and discussion}

\section{Characterization of graphene nanosheets and $\mathrm{SiCw}$}

The graphene have a distinct 2-D sheet structure, the size distribution of graphene nanosheets is nearly homogeneous, most of them distribute in about $10 \mu \mathrm{m}$ and six layers (Fig. 3a and $\mathrm{b}, \mathrm{S} 1 \dagger)$. The structures and the defect density of graphene nanosheets were characterized by Raman spectra (Fig. 3d), D peaks appearing at $1350 \mathrm{~cm}^{-1}$, are ascribed to the amorphous carbon and lattice defects in the graphene. $G$ peaks appearing at $1581 \mathrm{~cm}^{-1}$, caused by the vibrational mode of the phonon $\mathrm{E}_{2 \mathrm{~g}}$ in the hexagonal graphene structure, which is the $\mathrm{sp}^{2}$ vibrational characteristic peak of carbon. ${ }^{24,25}$ The D-to-G peak intensity ratio is as low as 0.19 , indicating that the graphene nanosheets have low defect densities, ${ }^{26}$ which is good for heat conduction compared with high defect densities in the polymer composites. ${ }^{27}$ Besides, the SiCw have a distinct 1-D whisker-like structure (Fig. 3c), the aspect ratio is 20. The size of graphene nanosheets and SiCw is consistent with the data provided by the manufacturer.

\section{TC of PG composites}

The TC of the PA composites were measured by a "laser flash" technique. The thermal conductivity is obtained by the formula: $\mathrm{K}=\alpha \times \rho \times C_{\mathrm{p}}$, where $\alpha$ is the thermal diffusivity, $\rho$ is the mass density and $C_{\mathrm{p}}$ is the specific heat of the sample. The detailed mechanism and methodology of the laser flash system have ever been reported in our previous study ${ }^{27,28}$ (Fig. S2 $\dagger$ ). XRD spectrum was used to characterize the physical form of matter in the polymer composites. From the XRD spectrum (Fig. 4), pure PA are observed with peaks at $2 \theta=20.5^{\circ}$ and 24.7 , corresponding to (200) and (002) reflections of $\alpha$-form crystal, respectively. ${ }^{29}$
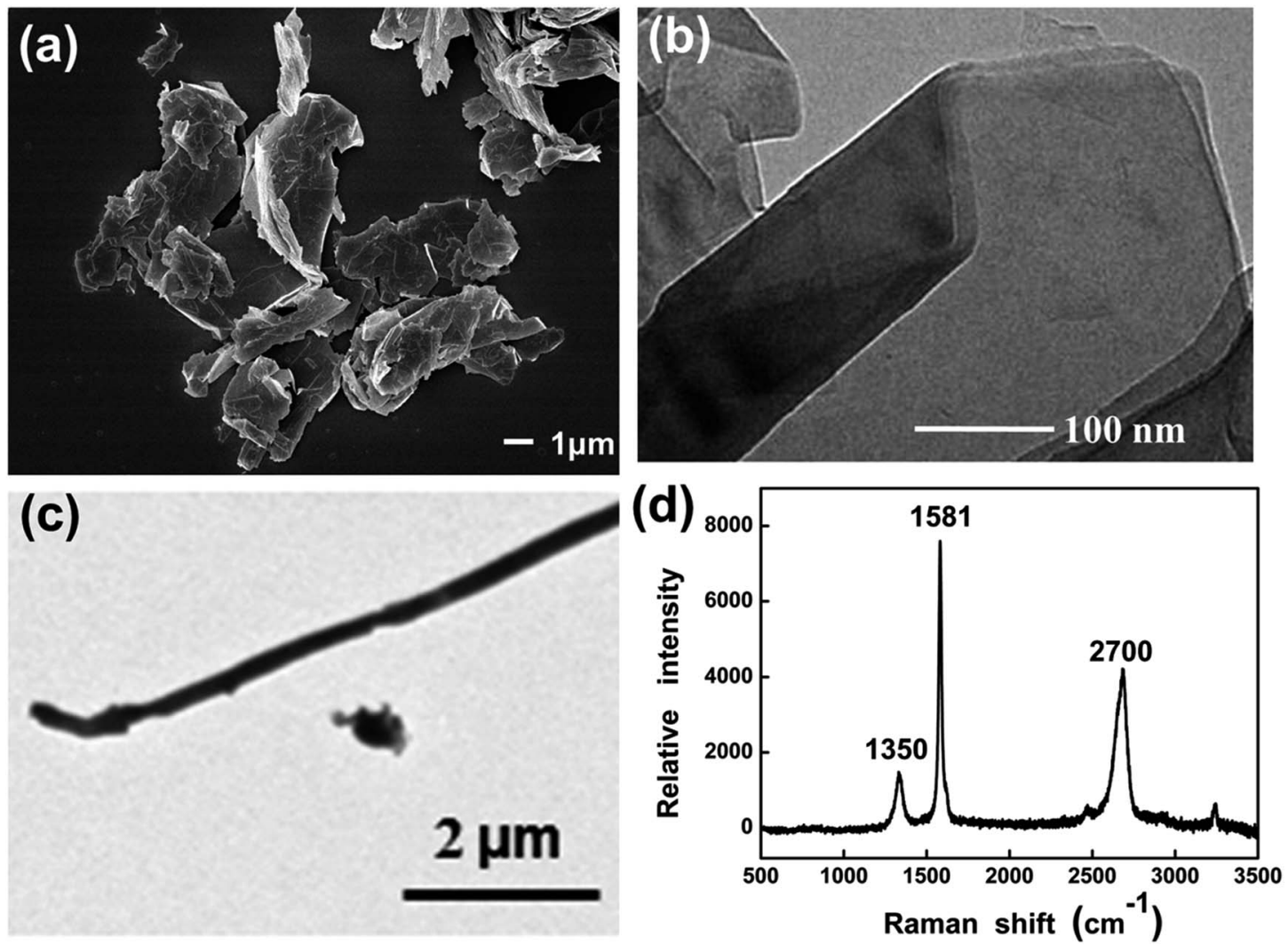

Fig. 3 Characterization of fillers (a) the SEM image of the graphene nanosheets (b) the HRTEM image of the graphene nanosheets (c) the TEM image of the SiCW (d) the Raman spectrum of the graphene nanosheets. 


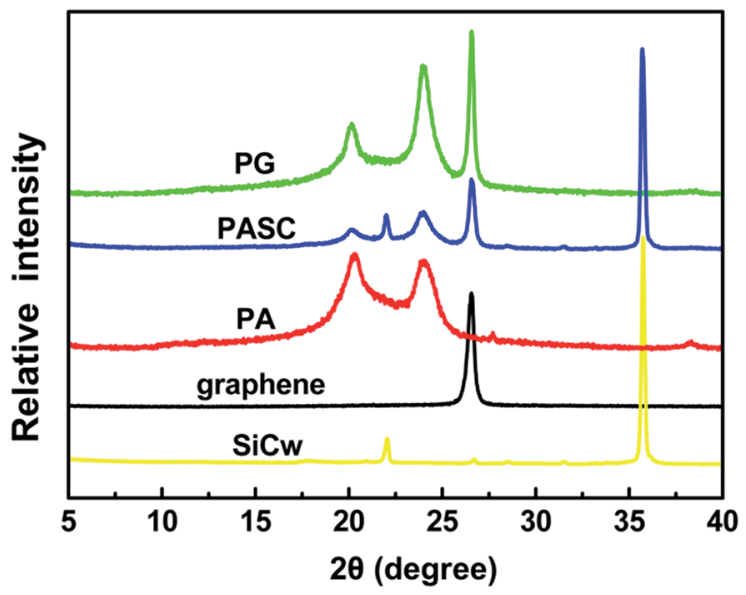

Fig. 4 XRD spectrum of the graphene nanosheets, SiCw, pure PA and PA composites.

Both of the graphene and PG composite are observed with peaks at $2 \theta=25.6^{\circ}$, which $\mathrm{d}$-spacing is $3.46 \AA$, corresponding with the thickness of a layer of graphene ${ }^{30}$. The detailed TC values of the PG composite can be found in Fig. 5a and Table S1. $\dagger$ The $\lambda_{x}$ of pure PA was $2.98 \mathrm{~W} \mathrm{~m}^{-1} \mathrm{~K}^{-1}$, which is similar to the value that we have ever reported. ${ }^{14}$

With the increase of filler content, the $\lambda_{x}$ and $\lambda_{z}$ of the PG composites increase consistently. When $3 \mathrm{wt} \%$ of graphene nanosheets were added in PA matrix, the $\lambda_{x}$ can reach as high as $7.81 \mathrm{~W} \mathrm{~m}^{-1} \mathrm{~K}^{-1}$, the $\lambda_{z}$ is $0.58 \mathrm{~W} \mathrm{~m}^{-1} \mathrm{~K}^{-1}$. The enhancement of the TC are generated by the high TC filler of graphene in the polymer composite. ${ }^{31,32}$ Obviously compared with the $\lambda_{z}$, the $\lambda_{x}$ of all the composites are higher (Fig. 5a). It is caused by the anisotropic thermal conduction of the graphene in the polymer composites. ${ }^{19}$ The TC of the polymer is determined by vibration of the of the phonon. ${ }^{33}$ The in-plane direction of graphene nanosheets is a perfect carbon-carbon conjugate structure, the vibration of the phonon is high, leading a good $\lambda_{x}$. Contrastly, there is a van der Waals' force on the through-plane direction, which can not form an effective heat conduction channel, leading to a low $\lambda_{z}^{34,35}$ (Fig. 6). During the hot-pressing, the orientation of graphene in PA matrix were formed, which can be seen in the Fig. $7 b$, graphene has a linear lamellar structure distribution in it, giving rise to a more obvious anisotropic TC. ${ }^{36}$ It is worth noting that the TC increase rapidly with introduction of a little graphene nanosheets, while the addition of graphene content exceeding $0.5 \mathrm{wt} \%$, the TC increase slowly both in the in-plane and through-plane direction. It may be caused by the aggregation of graphene nanosheets due to the van der Waals force between layers during the melting processing, ${ }^{34}$ which is not beneficial to build a thermal path.

\section{TC of PASC composites}

The low $\lambda_{z}$ value of PG composites is due to the anisotropic thermal conduction of graphene and its orientation in the PA matrix, ${ }^{37}$ which is inevitable during melting processing and hotpressing process. Obviously, the low TC, especially in the through-plane direction, limits the application of PA composites in the thermal management systems. Therefore, in this
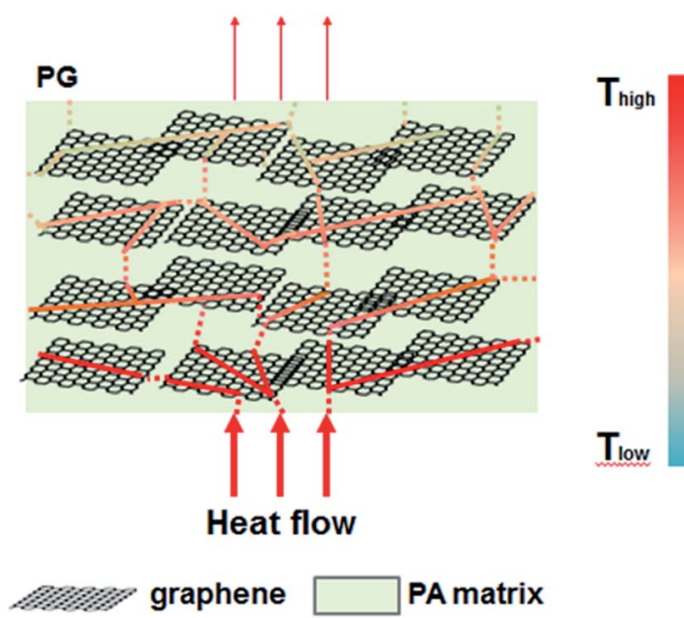

Fig. 6 The model of thermal conduction: the thermal path in the PG composites.
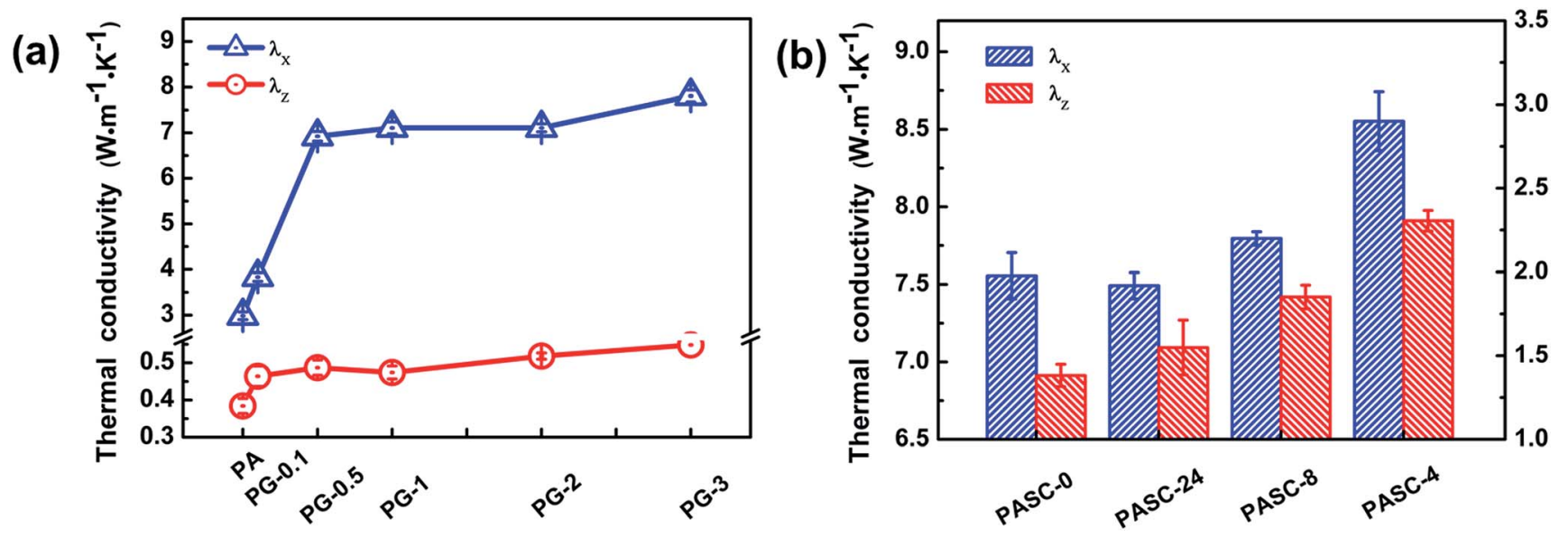

Fig. 5 The TC of the PA composites in the two direction (a) PG composites (b) PASC composites. 
(a)

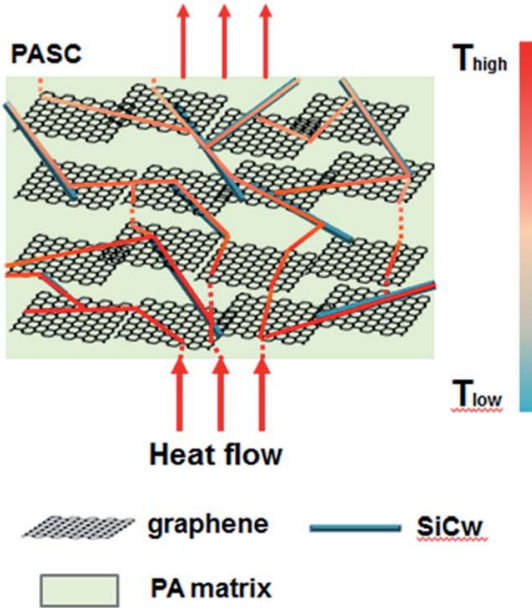

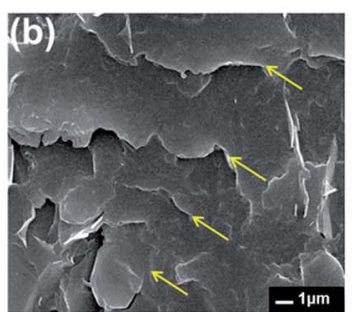
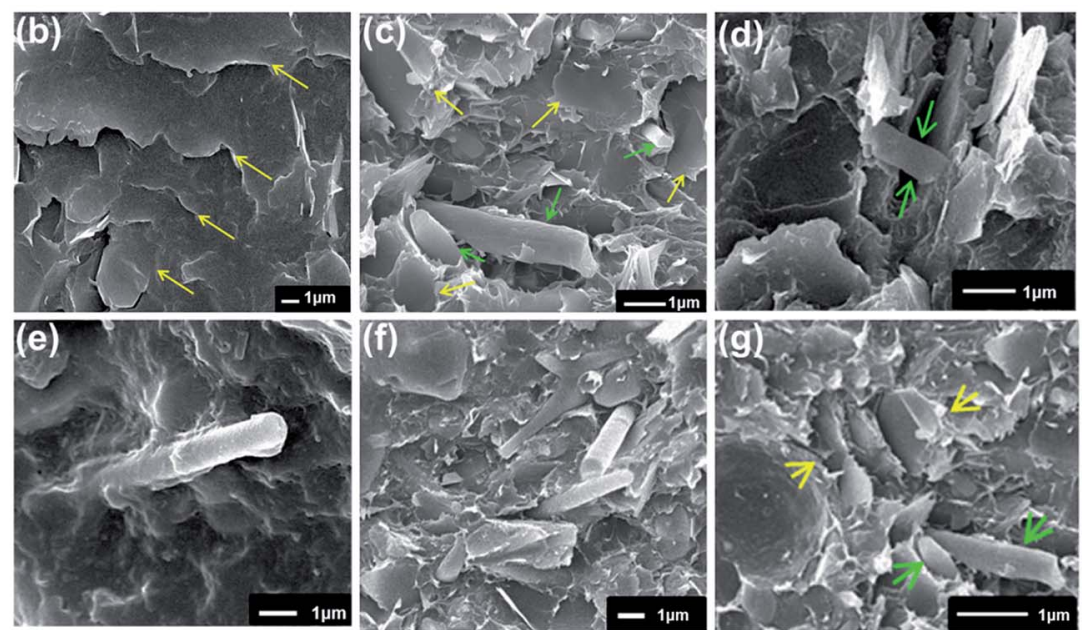

Fig. 7 (a)The model of thermal conduction: the thermal path in the PASC composites and the SEM images of the PA composites (the yellow arrow represents graphene nanosheets, the green arrow represents SiCW) (b) PG composites (layered structure) (c) the hybrid structure of the PASC composites (d), (e), (f) the 1-D SiCw between 2-D graphene nanosheets (g) the layered structure of the PASC composites.

section, the bridge effect of SiCw on the enhancement of thermal conductivity of PG composites were studied. The XRD spectrum of PASC (Fig. 4) is almost identical to the PG, in addition to that, there are two new peaks in the spectrum, which are similar to the characteristic peaks of $\mathrm{SiCw}^{38}$ indicating that $\mathrm{SiCw}$ is filled inside the PA composites. The TC values of the PASC composites are shown in the Fig. $5 \mathrm{~b}$ and Table S2. $\dagger$ The $\lambda_{z}$ of PASC- 24 is $1.55 \mathrm{~W} \mathrm{~m}^{-1} \mathrm{~K}^{-1}$, compared with the PG-2, the TCE is $199 \%$. Contrastly, the $\lambda_{x}$ of the above composites increase from $7.11 \mathrm{~W} \mathrm{~m}^{-1} \mathrm{~K}^{-1}$ to $7.49 \mathrm{~W} \mathrm{~m}^{-1} \mathrm{~K}^{-1}$, the TCE is just $5.4 \%$. With the increasement of the ratio of graphene to SiCw, the maximum $\lambda_{x}$ and $\lambda_{z}$ of PSAC-4 can reaches 8.55 and $2.31 \mathrm{~W} \mathrm{~m}^{-1}$ $\mathrm{K}^{-1}$, respectively, which can meet the need of electronic applications. ${ }^{7}$ Some articles have been reported this bridge effect, ${ }^{20,21}$ however, they are either bad bridge effect or expensive raw materials. Evidently, the TC and TCE of the PASC composite is one of the highest values ever reported for the composite of two kind fillers (Table 1).

In contrast with the PG composites, an interesting phenomenon appeared: the TC of the PG composites in the through-plane direction was enhanced effectively with the addition of SiCw, it mainly caused by the following reasons: Fig. $7 \mathrm{c}-\mathrm{g}$ show that under the shearing force of the Internal mixer, the 1-D SiC whiskers could filled the gap of the 2-D graphene nanosheets, especially in the through-plane direction, it can be observed that the columnar structures with vertical erects are sandwiched between the graphene nanosheets (Fig. 7d-f). Its two end junctions may be formed the hydrogen bonds with graphene nanosheets, and then combined more closely (Fig. S3†) and a SiCw thermally conductive paths is constructed in the through-plane direction. Just like $\mathrm{Liu}^{45}$ reported that the cross-linkers are effective paths for transmitting the through-plane direction phonon modes of graphene, but ineffective for the in-plane modes. Moreover, Varshney ${ }^{46}$ explained this phenomenon from the molecular dynamic simulations and constructed "pillared-graphene" architecture through combined carbon nanotube (CNT) with graphene in the through-plane direction, which is same with the model constructed (Fig. 7a). The scattering of the through-plane direction phonons occurs at long distances (at the junctions), and thus improving the overall phonon mean-free-path and increasing $\lambda_{z}$. With the help of hot pressing, the PASC

Table 1 The TC and TCE of the two fillers compared with one filler in the through-plane direction

\begin{tabular}{|c|c|c|c|c|c|c|}
\hline TCE(\%) & $\lambda_{z}\left(\mathrm{~W} \mathrm{~m}^{-1} \mathrm{~K}^{-1}\right)$ & $\begin{array}{l}\text { Total content } \\
\text { and the ratio }\end{array}$ & $\begin{array}{l}\text { Two filler synergistic } \\
\text { in the matrix }\end{array}$ & $\begin{array}{l}\text { One filler in } \\
\text { the matrix }\end{array}$ & Matrix & Ref. \\
\hline 35.8 & 1.48 & $60 \mathrm{wt} \%(1: 9)$ & $\mathrm{BN}$ and $\mathrm{T}-\mathrm{ZnO}$ & $\mathrm{BN}$ & $\mathrm{PF}$ & 20 \\
\hline$\sim 18.8$ & 0.808 & $50 \mathrm{wt} \%(4: 1)$ & $\mathrm{BN}$ and $\mathrm{Al}_{2} \mathrm{O}_{3}$ & $\mathrm{BN}$ & Epoxy & 39 \\
\hline 23 & $\sim 0.55$ & 35 wt\% $(6: 1)$ & BN and MWCNT & $\mathrm{BN}$ & iPP & 40 \\
\hline 38 & 0.662 & 21.5 wt\% $(20: 1.5)$ & Graphene and BN & Graphene & PS & 41 \\
\hline$\sim 71.4$ & $\sim 0.6$ & $35 \mathrm{wt} \%(6: 1)$ & Graphite and CF & Graphite & PA & 44 \\
\hline 199 & 1.55 & 45 wt\% (1:24) & Graphene and SiCw & Graphene & PA & This work \\
\hline 508 contrast with matrix & 2.31 & $45 \mathrm{wt} \%(1: 4)$ & Graphene and $\mathrm{SiCw}$ & Graphene & PA & \\
\hline
\end{tabular}




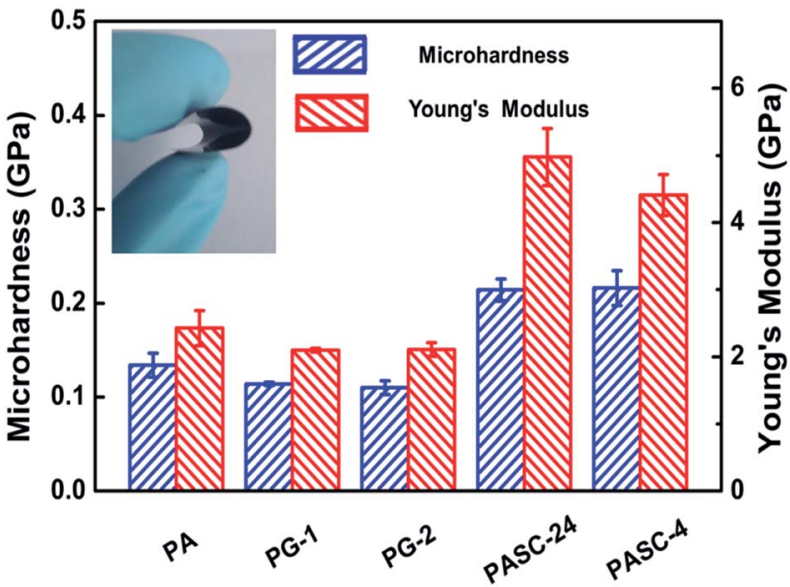

Fig. 8 Mechanical properties of Young's modulus and microhardness for the PA composites by nano-indentation technique (insets is the image of bending PASC film).

composites formed a ordered layered structure, which can be seen in the Fig. $7 \mathrm{~g}$, and the TCE of the through-plane direction exceed its in-plane direction. ${ }^{47,48}$ It may be caused that the 1- D $\mathrm{SiCw}$ filled the gap between the 2-D graphene nanosheets and then formed a good TC channel in the through-plane direction. It is worth pondering that the filler used in this paper has reached $45 \mathrm{wt} \%$. How to use a lower filler to achieve this effect is worthy of future research.

\section{The mechanical properties of the composites}

To achieve a better bridge effect to enhance the TC of the PG composites, more fillers (up to $45 \mathrm{wt} \%$ ) were added into the PA composites. ${ }^{40}$ High filler loading may result in the loss of mechanical properties of the polymer composites, nonetheless, in this work we achieve a synergistic effect that mechanical properties are enhanced with the TC increase simultaneously, including well bending toughness. Fig. 8 displays Young's modulus $(E)$ and microhardness $(H)$ of the composites by nanoindentation technique, which is widely used to characterize the mechanical behavior of materials at small scales. ${ }^{49}$ The Young's modulus $(E)$ and microhardness $(H)$ of the PA is $2.43 \mathrm{GPa}$ and $0.134 \mathrm{GPa}$, respectively, which is similar with the value that we ever reported. ${ }^{41}$ It can be found that the mechanical properties of the PG composites is a little bit down, which may relate to the decreasing of crystallinity caused by the incorporation of graphene. ${ }^{29}$ Compared with the PG-2 the Young's modulus and microhardness of the PASC-24 increase from 2.11 to $4.98 \mathrm{GPa}$ and from 0.11 to $0.214 \mathrm{GPa}$, improvements of 136 and $94.5 \%$, respectively, the bridge effect is significantly. This result can be ascribed that the 1-D SiCw filled the gap between the 2-D graphene nanosheets to prevent the accumulation of graphene and constructed a 3-D structure to resist the pressure.

\section{Conclusion}

In this work, we achieve a bridge effect of SiCw on the enhancement of TC in the PG composites. It is a time- and cost- efficient approach to manufacture the PASC composite through the Internal mixer. From the characterization and analysis, a conclusion was acquired that the SiCw could filled the gap between the graphene nanosheets, especially in the throughplane direction to prevent the accumulation of graphene, and a thermally conductive path is constructed in the through-plane direction. The TCE of the through-plane direction can reaches as high as $199 \%$, the maximum can reach $508 \%$ related to PA matrix. The value of the TC can reach the need of the electronic application. Meanwhile, the mechanical properties of the composites are synchronously enhanced. Beyond that it has practical value in large quantities of industrial production without use of any organic reagents and catalysts.

\section{Conflicts of interest}

There are no conflicts to declare.

\section{Acknowledgements}

This work was financially supported by the Natural Science Foundation of Shanghai (No. 17ZR1440700), the Program of Shanghai Academic/Technology Research Leader (No. 17XD1424400), the PetroChina Innovation Foundation (No. 2016D-5007-0508), the Program of university-industry cooperation of Shanghai Baoshan District (No. bkw2015136). National Natural Science Foundation of China (No. 51703122). The authors thank Prof. Yanyan Lou and Prof. Jie Li for help with the SEM and Micro-mechanical properties measurements.

\section{References}

1 Z. Yan, G. Liu, J. M. Khan and A. A. Balandin, Nat. Commun., 2012, 3, 827.

2 A. Moisala, Q. Li, I. A. Kinloch and A. H. Windle, Compos. Sci. Technol., 2006, 66, 1285-1288.

3 F. Monteverde and L. Scatteia, J. Am. Ceram. Soc., 2007, 90, 1130-1138.

4 Z. Han and A. Fina, Prog. Polym. Sci., 2011, 36, 914-944.

5 H. Chen, V. V. Ginzburg, J. Yang, Y. Yang, W. Liu, Y. Huang, L. Du and B. Chen, Prog. Polym. Sci., 2016, 59, 41-85.

6 X. Y. Huang, P. K. Jiang and T. Tanaka, IEEE Electr. Insul. Mag., 2011, 27, 8-16.

7 F. Danes, B. Garnier and T. Dupuis, Int. J. Thermophys., 2003, 24, 771-784.

8 W.-L. Song, L. M. Veca, C. Y. Kong, S. Ghose, J. W. Connell, P. Wang, L. Cao, Y. Lin, M. J. Meziani, H. Qian, G. E. LeCroy and Y.-P. Sun, Polymer, 2012, 53, 3910-3916.

9 G. Droval, J. F. Feller, P. Salagnac and P. Glouannec, e-Polym., 2009, 17.

10 A. K. Geim and K. S. Novoselov, Nat. Mater., 2007, 6, 183-191.

11 K. S. Novoselov, V. I. Fal'ko, L. Colombo, P. R. Gellert, M. G. Schwab and K. Kim, Nature, 2012, 490, 192-200.

12 R. Prasher, Science, 2010, 328, 185-186.

13 A. A. Balandin, S. Ghosh, W. Z. Bao, I. Calizo, D. Teweldebrhan, F. Miao and C. N. Lau, Nano Lett., 2008, 8, 902-907. 
14 N. Song, J. Yang, P. Ding, S. Tang and L. Shi, Composites, Part A, 2015, 73, 232-241.

15 Y. Fu, L. Liu, J. Zhang and W. C. Hiscox, Polymer, 2014, 55, 6381-6389.

16 J. Gu, N. Li, L. Tian, Z. Lv and Q. Zhang, RSC Adv., 2015, 5, 36334-36339.

17 J. Gu, X. Yang, Z. Lv, N. Li, C. Liang and Q. Zhang, Int. J. Heat Mass Transfer, 2016, 92, 15-22.

18 W. Park, J. N. Hu, L. A. Jauregui, X. L. Ruan and Y. P. Chen, Appl. Phys. Lett., 2014, 104, 4.

19 X. Tian, M. E. Itkis, E. B. Bekyarova and R. C. Haddon, Sci. Rep., 2013, 3, 1710.

20 F.-Y. Yuan, H.-B. Zhang, X. Li, X.-Z. Li and Z.-Z. Yu, Composites, Part A, 2013, 53, 137-144.

21 A. Yu, P. Ramesh, X. Sun, E. Bekyarova, M. E. Itkis and R. C. Haddon, Adv. Mater., 2008, 20, 4740-4744.

22 S.-Y. Yang, W.-N. Lin, Y.-L. Huang, H.-W. Tien, J.-Y. Wang, C.-C. M. Ma, S.-M. Li and Y.-S. Wang, Carbon, 2011, 49, 793-803.

23 M. Shtein, R. Nadiv, M. Buzaglo, K. Kahil and O. Regev, Chem. Mater., 2015, 27, 2100-2106.

24 A. C. Ferrari and D. M. Basko, Nat. Nanotechnol., 2013, 8, 235-246.

25 L. M. Malard, M. A. Pimenta, G. Dresselhaus and M. S. Dresselhaus, Phys. Rep., 2009, 473, 51-87.

26 L. G. Cancado, A. Jorio, E. H. Martins Ferreira, F. Stavale, C. A. Achete, R. B. Capaz, M. V. O. Moutinho, A. Lombardo, T. S. Kulmala and A. C. Ferrari, Nano Lett., 2011, 11, 3190-3196.

27 N. Song, S. Cui, D. Jiao, X. Hou, P. Ding and L. Shi, Carbon, 2017, 115, 338-346.

28 N. Song, D. Jiao, S. Cui, X. Hou, P. Ding and L. Shi, ACS Appl. Mater. Interfaces, 2017, 9, 2924-2932.

29 P. Ding, N. Zhuang, X. Cui, L. Shi, N. Song and S. Tang, J. Mater. Chem. C, 2015, 3, 10990-10997.

30 M. Liu, Y. Song, S. He, W. W. Tjiu, J. Pan, Y. Y. Xia and T. Liu, ACS Appl. Mater. Interfaces, 2014, 6, 4214-4222.

31 C.-C. Teng, C.-C. M. Ma, C.-H. Lu, S.-Y. Yang, S.-H. Lee, M.-C. Hsiao, M.-Y. Yen, K.-C. Chiou and T.-M. Lee, Carbon, 2011, 49, 5107-5116.
32 S. H. Song, K. H. Park, B. H. Kim, Y. W. Choi, G. H. Jun, D. J. Lee, B. S. Kong, K. W. Paik and S. Jeon, Adv. Mater., 2013, 25, 732-737.

33 A. A. Balandin, Nat. Mater., 2011, 10, 569-581.

34 V. V. Gobre and A. Tkatchenko, Nat. Commun., 2013, 4, 2341. 35 M. J. Biercuk, M. C. Llaguno, M. Radosavljevic, J. K. Hyun, A. T. Johnson and J. E. Fischer, Appl. Phys. Lett., 2002, 80, 2767-2769.

36 P. Ding, S. Su, N. Song, S. Tang, Y. Liu and L. Shi, Carbon, 2014, 66, 576-584.

37 P. Ding, J. Zhang, N. Song, S. Tang, Y. Liu and L. Shi, Compos. Sci. Technol., 2015, 109, 25-31.

38 W. W. Wu, J. Y. Gui, T. B. Zhu and Z. P. Xie, Ceram. Int., 2016, 42, 16332-16335.

39 L. Fang, C. Wu, R. Qian, L. Xie, K. Yang and P. Jiang, $R S C$ Adv., 2014, 4, 21010-21017.

40 S.-L. Zhong, Z.-Y. Zhou, K. Zhang, Y.-D. Shi, Y.-F. Chen, X.-D. Chen, J.-B. Zeng and M. Wang, RSC Adv., 2016, 6, 98571-98580.

41 X. Cui, P. Ding, N. Zhuang, L. Shi, N. Song and S. Tang, ACS Appl. Mater. Interfaces, 2015, 7, 19068-19075.

42 L. Shao, L. Shi, X. Li, N. Song and P. Ding, Compos. Sci. Technol., 2016, 135, 83-91.

43 D. Shimamoto, Y. Imai and Y. Hotta, J. Ceram. Soc. Jpn., 2014, 122, 732-735.

44 Y. Yoo, H. L. Lee, S. M. Ha, B. K. Jeon, J. C. Won and S.-G. Lee, Polym. Int., 2014, 63, 151-157.

45 X. Liu, G. Zhang and Y.-W. Zhang, J. Phys. Chem. C, 2014, 118, 12541-12547.

46 V. Varshney, S. S. Patnaik, A. K. Roy, G. Froudakis and B. L. Farmer, ACS Nano, 2010, 4, 1153-1161.

47 B. Ashrafi, A. M. Díez-Pascual, L. Johnson, M. Genest, S. Hind, Y. Martinez-Rubi, J. M. González-Domínguez, M. Teresa Martínez, B. Simard, M. A. Gómez-Fatou and A. Johnston, Composites, Part A, 2012, 43, 1267-1279.

48 A. M. Diez-Pascual and M. Naffakh, ACS Appl. Mater. Interfaces, 2013, 5, 9691-9700.

49 W. C. Oliver and G. M. Pharr, J. Mater. Res., 1992, 7, 15641583. 